Check for updates

Cite this: RSC Adv., 2017, 7, 32574

Received 27th April 2017

Accepted 14th June 2017

DOI: $10.1039 / \mathrm{c} 7 \mathrm{ra04730d}$

rsc.li/rsc-advances

\section{Graphene oxide/carboxyl-functionalized multi- walled carbon nanotube hybrids: powerful additives for water-based lubrication}

\author{
Chunying Min, (D)* Qiaqia Zhang, Chen Shen, Dengdeng Liu, Xiaojuan Shen, \\ Haojie Song, Songjun Li, Dong Xu, Xingyu Lin and Kan Zhang (D)*
}

\begin{abstract}
The development of water-based lubricants with well dispersed ultrafine particles is in high demand. In this article, graphene oxide (GO) nanosheets/carboxyl-functionalized multi-walled carbon nanotubes (MWCNTs-COOH) hybrids have been synthesized via vacuum filtration of a solution hybrid dispersion, as additives for water-based lubricants. The tribological performance of GO/MWCNTs-COOH hybrids in water was systematically investigated. The lubrication properties of water-based lubricant can be significantly improved by adding GO/MWCNTs-COOH hybrids in comparison with adding only GO nanosheets or MWCNTs-COOH as lubricant additives. Notably, the water with as little as 0.7 wt\% of GO/ MWCNTs- $\mathrm{COOH}$ hybrids exhibits the best lubrication performance in terms of friction and wear reduction. This unique tribological performance of GO/MWCNTs- $\mathrm{COOH}$ hybrids in water suggests the existence of a synergistic effect of $\mathrm{GO}$ and MWCNTs-COOH on reducing friction and wear.
\end{abstract}

\section{Introduction}

Lubricants are mainly composed of mineral oil or synthetic oil with various additives. With the continuous decrease of global oil reserves, the energy crisis has been triggered. ${ }^{1,2}$ Besides, due to leakage, infiltration and other reasons, amounts of lubricants and chemical agents are discharged into the natural environment, causing harm to human health and also environmental problems. ${ }^{3,4}$ Therefore, the development of green and sustainable lubricants is highly demanded all around the world.

Recently, water-based lubricants have become a series of new and promising high performance lubricants with applications in hydraulic fluid, cutting fluid, and the oil extraction industry owing to its high thermal conductivity, low working temperature, and its endless resources. However, low corrosion resistance and high wear rate limit its wider applications. At present, various forms of carbon-based nanomaterials (i.e., nano-tube, nanoonions, nano-diamond, etc.) are used to reduce friction and wear and this has gained high attention..$^{5-8}$ Compared to traditional metal $(\mathrm{Cu}, \mathrm{Ag}, \mathrm{Al})$ and their corresponding oxide nanoparticles $\left(\mathrm{CuO}, \mathrm{Al}_{2} \mathrm{O}_{3}, \mathrm{Ag}_{2} \mathrm{O}\right)$, carbon-based nanomaterials exhibit unique properties including high corrosion resistance, strong environmental adaptability, outstanding tribological properties and good dispersibility with water-based lubricants, leading their enhanced lubrication properties under different conditions.

Institute of Polymer Materials, School of Material Science and Engineering, Jiangsu University, Zhenjiang, Jiangsu, 212013, P. R. China. E-mail: mj790206@ujs.edu.cn; zhangkan@ujs.edu.cn
Carbon nanotubes (CNTs), a one-dimensional nano carbon material, offers extraordinary physical and chemical properties, such as corrosion resistance, high temperature resistance, heat resistance, good thermal and electrical conductivity, lubricity, etc. ${ }^{9-11}$ CNT can be a potential candidate as water-based lubricant additive after modification with hydrophilic functionalities. Meng et al. ${ }^{12}$ found that CNTs could improve the wear resistance as well as reduce the friction coefficient of polyamide 6 considerably under both dry sliding and water-lubricated conditions. However, Shen et al. ${ }^{13}$ reported that CNTs could not improve the lubricating performance of nanofluids because of high friction between molecules and high molecular strength. In our previous study, we discovered that the incorporation of carboxyl-functionalized multi-walled carbon nanotubes (MWCNTs-COOH) can significantly enhance the mechanical properties and thermal stability of polyimides. ${ }^{14}$

Hybrid nanocomposites have recently attracted a large number of researchers' interests with various combinations of mixtures being studied, for instance, MWCNT with carbon black, ${ }^{15}$ few layer graphene with single walled CNT and nano diamonds ${ }^{16}$ and MWCNT with graphene nanoplatelets (GnP). ${ }^{17} \mathrm{~S}$. Chatterjee et al. ${ }^{18}$ have found a synergistic effect of CNT and GnP on epoxy composites. It has been extensively reported that modified nanocarbon materials can improve their compatibility with waterbased lubricants. In addition, graphene, ${ }^{19-22}$ a two-dimensional carbon material, has raised widespread concerns about its commendable properties, such as high thermal conductivity, high Young's modulus, large specific surface area and anti-wear properties. Graphene oxide (GO), as a derivative of graphene, has a large number of oxygen-containing functional groups on its 
plane, making it possess well water solubility and dispersibility. Thus, as additives in water-based lubricants, GO nanosheets are much more feasible compared with graphene. Song et al. ${ }^{23}$ investigated GO nanosheets and confirmed that they can improve the anti-wear and anti-friction properties in water. Besides, Sarno et $a .^{24}$ studied the GO sheets as additives in oil-based lubricants. Oskari Elomaa et al. ${ }^{25}$ have found that the water-based lubricants with dispersed GO exhibit lower friction in diamond-like carbon in comparision with stainless steel tribological contacts. Moreover, Cote $^{26}$ has illustrated that graphene oxide as surfactant sheets can improve the water solubility of carbon nanotubes, and non-metallic carbon materials as additives only containing $\mathrm{C}, \mathrm{H}$ and $\mathrm{O}$ instead of heavy metal elements and toxic particles coincide with the purpose of environmental protection. However, the flat shape of Go leads it readily sticking to each other, thereby decreasing the tribological performance of its corresponding lubricants. Interestingly, the crumpled graphene could exhibit advantages both in self-dispersion and aggregation resistance even without oxidation in oil, making it an attractive materials for tribological applications. ${ }^{27}$

From all these findings, we were encouraged to find a facile approach to prepare high-performance additives for water-based lubricants via CNT and graphene nanoparticles. In this study, GO/MWCNTs-COOH hybrids have been synthesized by vacuum filtration of solution hybrid dispersion and applied as waterbased lubricant additives. We demonstrate that GO/MWCNTs$\mathrm{COOH}$ hybrids as additives in water is indeed a superior friction modifier compared with both GO and MWCNTs-COOH particles. Remarkably, the water with as less as $0.7 \mathrm{wt} \%$ GO/MWCNTs$\mathrm{COOH}$ hybrids exhibits the best lubrication performance in terms of friction and wear reduction. Furthermore, the tribological mechanism of GO/MWCNTs-COOH hybrids has also been proposed.

\section{Experimental section}

\section{Preparation of MWCNTs-COOH}

$1.73 \mathrm{~g}$ MWCNT were treated with a mixed acid of and, in which the volume ratio of concentrated $\mathrm{HNO}_{3}$ and $\mathrm{H}_{2} \mathrm{SO}_{4}$ is $1: 3$. The mixture was kept at $80^{\circ} \mathrm{C}$ with mechanical agitation for $2 \mathrm{~h}$. The obtained suspension was diluted by pure water gradually until it cooled to room temperature. Then, the mixture was filtered, followed by repeated centrifugal washing until the $\mathrm{PH}$ of filtrate is neutral. At last, the product was dried in a vacuum oven at $60{ }^{\circ} \mathrm{C}$ for $24 \mathrm{~h}$ to gain the MWCNTs-COOH.

\section{Preparation of GO/MWCNTs-COOH hybrids}

GO nanosheets were prepared by a modified Hummers method. ${ }^{28}$ The as-prepared GO nanosheets and MWCNTs-COOH in a mass ratio of $1: 1,1: 3,1: 9,3: 1,9: 1$ were added together into alcohol under ultrasonication for $1 \mathrm{~h}$, respectively. Then, the above mixture was transferred into flask with vigorously mechanical stirring at $60{ }^{\circ} \mathrm{C}$ for $2 \mathrm{~h}$, followed by vacuum filtration. Lastly, the mixture was placed in a vacuum oven for $10 \mathrm{~h}$ at $60{ }^{\circ} \mathrm{C}$ to gain $\mathrm{GO} / \mathrm{MWCNTs}-\mathrm{COOH}$ hybrids samples. The hybrids were named as GO/MWCNTs-COOH-1-1, GO/MWCNTs-COOH-
1-3, GO/MWCNTs-COOH-1-9, GO/MWCNTs-COOH-3-1 and GO/ MWCNTs-COOH-9-1 according to the mass ratio between Go and MWCNTs-COOH.

\section{Tribological properties of GO/MWCNTs-COOH hybrids as water lubricant additives}

The as-prepared GO/MWCNTs-COOH hybrids were distributed into water respectively via $30 \mathrm{~min}$ ultrasonication to get a uniform and stable suspension. The above suspension is by mass fraction of $0.1 \%, 0.3 \%, 0.5 \%, 0.7 \%$ and $1.0 \%$. GO nanosheets and MWCNTs-COOH were processed by the same procedure.

Tribological properties of the above suspension samples with different weight concentrations of additives were tested using a universal micro-tribotester (UMT-2, Center for Tribology Inc., USA). The measurement for friction was conducted with a ball on the disc friction with a rotation speed of $0.0523 \mathrm{~m} \mathrm{~s}^{-1}$. The load force was keeping under a constant load of $10 \mathrm{~N}$ and the test duration was as long as $30 \mathrm{~min}$. The stainless steel ball with a diameter of $4 \mathrm{~mm}$ and a hardness of $61 \mathrm{HRC}$ was made of GCr15 bearing steel (AISI 52100). The rotation radius is $3 \mathrm{~mm}$. The steel balls and steel disc were cleaned by acetone and dried before tests. All the friction and wear tests of the samples were carried out in air at ambient temperature and a relative humidity of $50-60 \%$. The worn surfaces of steel ball were measured by Zeiss Observer Z1m metalloscope. Three-dimensional contours of wear track were measured by Keyence VHX-1000.

The wear volume V $\left(\mathrm{mm}^{3}\right)$ of worn surface of steel ball was calculated by following formula:

$$
V=\pi\left(R-\sqrt{R^{2}-r^{2}}\right)^{2}\left(R-\frac{R-\sqrt{R^{2}-r^{2}}}{3}\right)
$$

where $R$ is the radius of worn surface of the steel ball ( $\mathrm{mm}), r$ is the radius of wear spot $(\mathrm{mm})$.

The specific wear rate $K\left[\mathrm{~mm}^{3}(\mathrm{Nm})^{-1}\right]$ of counterpart steel ball surface was calculated according to the formula: ${ }^{29}$

$$
K=\frac{V}{L d}
$$

where $L$ is the normal load $(N)$ and $d$ is sliding distance $(m)$ of the wear test. The wear test of each samples were repeated three times.

\section{Characterization}

The Fourier transfer infrared (FTIR) spectra were carried out by AVATAR360 FT-IR spectrometer (USA Nicolet Instrument Corporation) in the range from 500 to $4000 \mathrm{~cm}^{-1}$. Raman spectra of GO, CNTs and GO/CNTS hybrids were obtained by Laser Raman Spectrometer with $532 \mathrm{~nm}$ laser excitation. Thermogravimetric (TGA) analysis was performed with STA449C analyser in the air with a scan rate of $10{ }^{\circ} \mathrm{C} \mathrm{min}^{-1}$ with the temperature ranging from 30 to $800{ }^{\circ} \mathrm{C}$. The morphology of the GO, MWCNTs-COOH and GO/MWCNTs-COOH hybrids was studied by scanning electron microscope (SEM) (JEOL JSM 6700F) and transmission electron microscope (TEM) operated at $200 \mathrm{kV}$. 


\section{Results and discussion}

To visually learn the dimensional self-construction of the assynthesized hybrids, the surface morphologies and configurations of the prepared GO nanosheets, MWCNTs-COOH and GO/ MWCNTs-COOH hybrids were performed by SEMand TEM, as shown in Fig. 1 and 2 for comparison. Layer structure can be observed for GO nanosheets as depicted in Fig. 1(a). AFM image in Fig. 1(b) also shows the prepared GO nanosheets are layered and the thickness of GO nanosheets in the current study is about $2.6 \mathrm{~nm}$. Besides, the pure MWCNTs- $\mathrm{COOH}$ are naturally entangled and disordered as shown in Fig. 1(c). Fig. 1(d) shows that the GO/MWCNTs-COOH-3-1 hybrids are well-assembled with MWCNTs-COOH hooked onto GO nanosheets. The condensation between the carboxyl groups of MWCNTs-COOH and the hydroxyl and epoxy groups of GO firmly anchors the CNT nanotubes to the graphene sheets. Borrowing from the interconnected network of GO/MWCNTs-COOH hybrids, the graphene sheets do not readily stick to each other (unlike flat sheets). Therefore, we expect that ultrafine particles of $\mathrm{GO} /$ MWCNTs-COOH hybrids should self-disperse in water and could act as irregular cubes to reduce friction and wear.

The configuration of GO/MWCNTs- $\mathrm{COOH}$ hybrids with different weight ratio of GO and MWCNTs- $\mathrm{COOH}$ was frontally observed by TEM (Fig. 2) in which the MWCNTs are grown on the surface of GO nanosheets. As the ratio of GO and MWCNTs$\mathrm{COOH}$ reaches $9: 1$, such low weight concentration of MWCNTs-COOH is not efficient to form uniform network as shown in Fig. 2(a). Besides, slight aggregation can be seen in Fig. 2(c), and MWCNTs-COOH aggregates seriously in Fig. 2(d). However, when the ratio of GO nanosheets and MWCNTs$\mathrm{COOH}$ is $3: 1$, the network of GO/MWCNTs-COOH hybrid seems more uniform as presented in Fig. 2(b).

Fig. 3 shows the Raman spectra of GO/MWCNTs-COOH hybrids derived from different weight ratios of GO and MWCNTs. The D-band at $1350 \mathrm{~cm}^{-1}$ represents the disordered
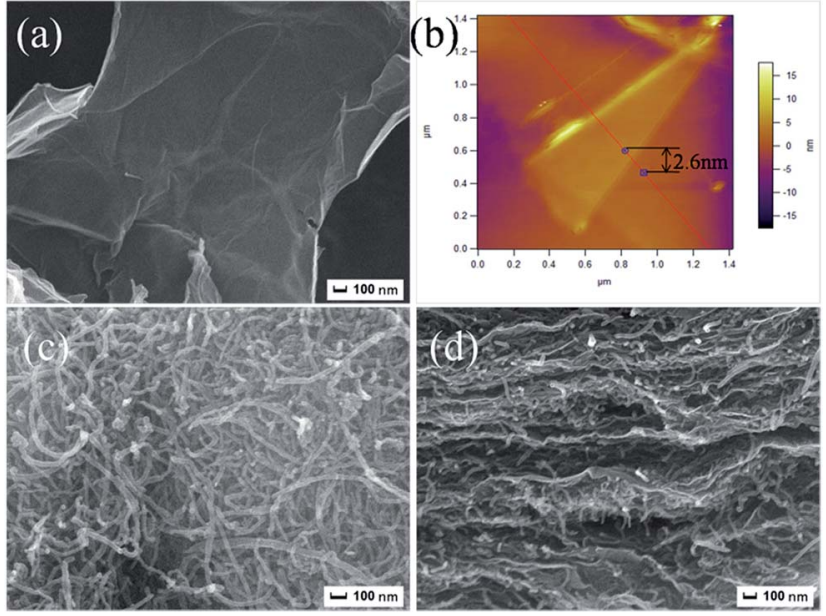

Fig. 1 SEM images of GO nanosheets (a), MWCNTs- $\mathrm{COOH}$ (c), crosssections of GO/MWCNTs- $\mathrm{COOH}-3-1$ hybrid (d), AFM images of GO nanosheets (b).
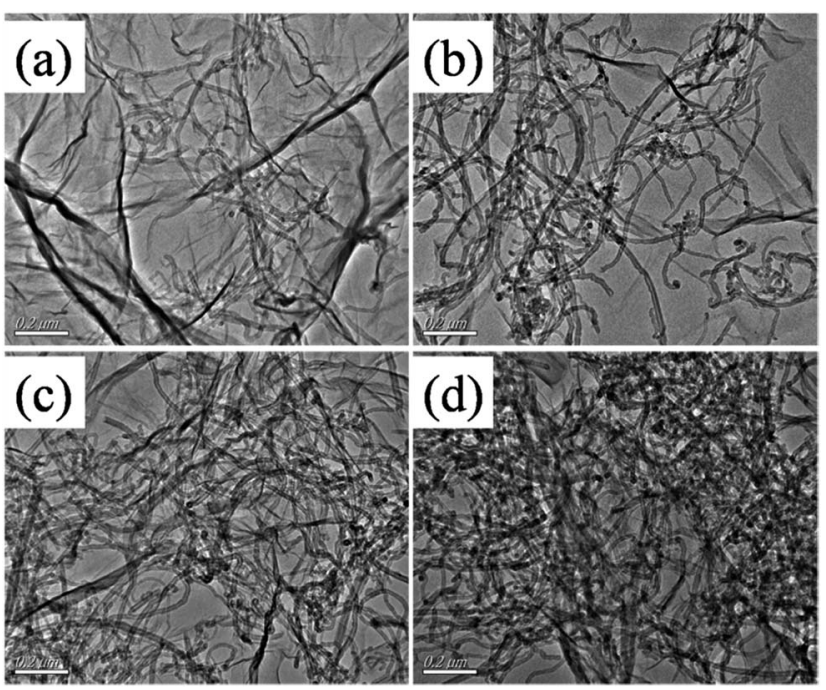

Fig. 2 TEM images of hybrids derived from different weight ratio (a) GO/MWCNTs-COOH hybrids-9-1, (b) GO/MWCNTs-COOH hybrids3-1, (c) GO/MWCNTs-COOH hybrids-1-1, (d) GO/MWCNTs-COOH hybrids-1-3.

$\mathrm{sp}^{3}$ structure and the G-band at $1590 \mathrm{~cm}^{-1}$ corresponds to the $\mathrm{sp}^{2}$ hybridized graphitic structure. ${ }^{30}$ It is noted that the intensity ratio of D-band and G-band $\left(I_{\mathrm{D}} / I_{\mathrm{G}}\right)$ can describe the defect of carbon structure. ${ }^{31,32}$ The ratio of $I_{\mathrm{D}} / I_{\mathrm{G}}$ of GO/MWCNTs-COOH3-1 was calculated as 0.94. In addition, the ratio of $I_{\mathrm{D}} / I_{\mathrm{G}}$ increases obviously as increasing the concentration of MWCNTS-COOH.

Powders of GO nanosheets, MWCNTs- $\mathrm{COOH}$ and $\mathrm{GO} /$ MWCNTs- $\mathrm{COOH}-3-1$ hybrids were sonicated in water until they were fully dispersed in water with no residual solids remaining. All three additives can initially disperse in the water right after sonication (Fig. 4(a-c)). The GO nanosheets solution exhibits brown color due to the loss of electronic conjugation by oxidation, carboxyl, hydroxyl and epoxy groups, which are grafted onto the edge and surfaces of GO nanosheets, making GO nanosheets partially hydrophilic that insure the stable dispersion in aqueous medium. ${ }^{23}$ CNTs after acidification also gained

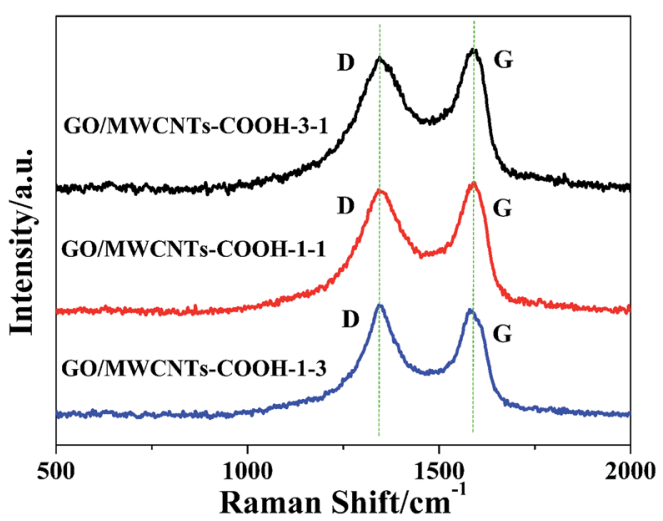

Fig. 3 Raman spectra of GO/MWCNTs-COOH-(3-1, 1-1, 1-3) hybrids. 


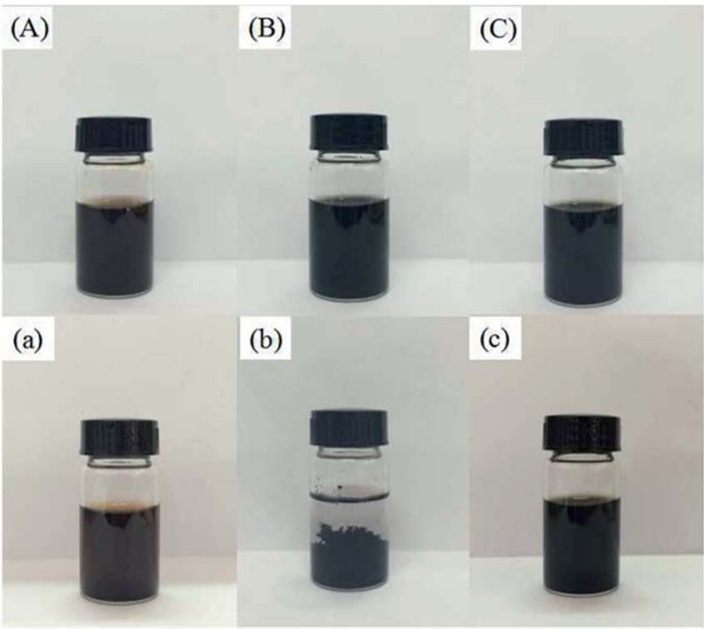

Fig. 4 Dispersion properties of various additives in water at $1.0 \mathrm{wt} \%$. Immediately after sonication for GO (A), MWCNTs- $\mathrm{COOH}$ (B) and GO/ MWCNTs- $\mathrm{COOH}-3-1$ hybrids (C) and 2 weeks after sonication for $\mathrm{GO}$ (a), MWCNTs- $\mathrm{COOH}$ (b) and GO/MWCNTs- $\mathrm{COOH}-3-1$ hybrids (c).

relatively stable water-soluble in a short-term. However, agglomeration was apparent after few days (Fig. 4(c)). After two weeks, GO and GO/MWCNTs-COOH hybrids were still dispersed in the water, but the $\mathrm{CNTs}-\mathrm{COOH}$ additives were fully sedimented as shown in Fig. 4(a-c). Fig. 4 indicates that GO nanosheets is capable of improving the dispersibility of MWCNTs-COOH in water, which is possible due to the $\pi-\pi$ interactions between the $\mathrm{CNTs}-\mathrm{COOH}$ and $\pi$ patches on GO basal plane. ${ }^{33}$ The superior self-disperse property in water of $\mathrm{GO} / \mathrm{MWCNTs}-\mathrm{COOH}$ hybrids suggests it as potential candidate for lubrication application.

The friction and wear behaviors of GO/MWCNTs- $\mathrm{COOH}$ hybrids were investigated as lubricant additives in pure water. The as-prepared GO/MWCNTs-COOH hybrids derived from different weight ratios $(1: 1,1: 3,1: 9,3: 1,9: 1)$ of GO and MWCNTs-COOH with a content of $0.3 \mathrm{wt} \%$ in water were chosen to evaluate the tribological properties. The friction coefficients and wear rates of water lubricants with additives of GO/MWCNTs-COOH hybrids are as shown in Fig. 5. It is obvious that the different ratio of GO nanosheets and MWCNTs-COOH significantly influences the tribological properties of water lubricants. Especially, as the weight ratio of GO and MWCNTs-COOH comes to $3: 1$, the water lubricant
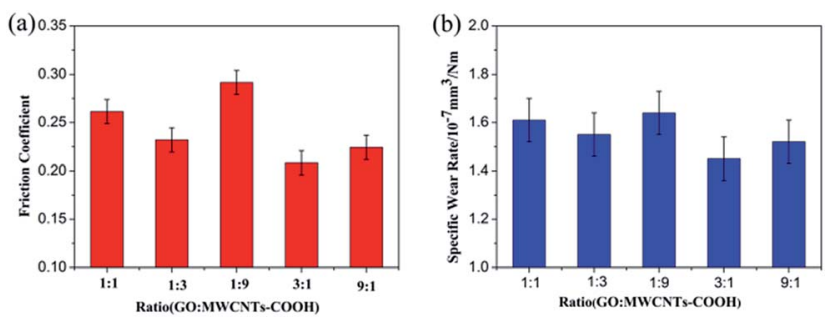

Fig. 5 Friction coefficients (a) and wear rates (b) of varying ratios of $\mathrm{GO} / \mathrm{MWCNTs}-\mathrm{COOH}$ hybrids dispersed in pure water. with GO/MWCNTs-COOH exhibits the best tribological performance with the lowest friction coefficient and wear rate. It indicates that the existence of the synergistic effect between GO nanosheets and MWCNTs-COOH leads superior tribological properties of water lubricants. In particular, the ratio of GO nanosheets and MWCNTs-COOH is an essential factor affecting the reinforcing capabilities of the hybrids. Previous report ${ }^{18}$ suggested that MWCNTs are readily assembled on the GO nanosheet surfaces, creating an inter-connected strong nanofiller network. Therefore, the homogeneous dispersion of particles causes improved lubrication properties.

To further investigate the lubrication performance of waterbased lubricants with GO/MWCNTs-COOH additives, we have systematically investigated the effect of different contents of GO/MWCNTs-COOH-3-1 hybrids on tribological properties. In addition, the triblogical properties of water-based lubricants with different contents of $\mathrm{GO}$ and $\mathrm{CNTs}-\mathrm{COOH}$ were also studied for comparison. As the three additives are dispersed in water, friction coefficients of water-based lubricants show a decrease trend going with the increase of contents in Fig. 6(a). When content of additives is less or equal to $0.5 \mathrm{wt} \%$, friction coefficient of water with GO nanosheets is lower than the other two lubricants. However, as the content of additives reaches more than $0.5 \mathrm{wt} \%$, the friction coefficient of lubricant with $\mathrm{GO} /$ MWCNTs-COOH-3-1 hybrids exhibits much lower than that of GO and MWCNTs-COOH, and the friction coefficient of water with 0.7 wt $\%$ GO/MWCNTs-COOH-3-1 hybrids reaches minimum. Observed from Fig. 6(b), all of the three carbon materials can reduce wear rates visibly, in which abrasive resistance of GO/MWCNTs-COOH hybrids is superior to GO and MWCNTs- $\mathrm{COOH}$ as additives. Furthermore, the wear rates of GO/MWCNTs-COOH-3-1 hybrids as water-based lubricant additives are very stable with the increase of weight concentration. Thus, $0.7 \mathrm{wt} \%$ of GO/MWCNTs-COOH-3-1 hybrids as additive exhibits the most excellent tribological performance.

The worn surface of steel ball and the three-dimensional profile of wear track of counterparts under water-based lubrication were displayed in Fig. 7(a-d). Therein, wear spot diameter of worn surface of steel ball under pure water in Fig. 7(a) is larger, wear track is deeper, and visible wear degree is distinct. The worn surface of steel ball under $0.7 \mathrm{wt} \% \mathrm{GO}$ nanosheets, 0.7 wt $\%$ MWCNTs-COOH and 0.7 wt\% GO/MWCNTs-COOH-3-1 hybrids as additives added in pure water were shown in (a)

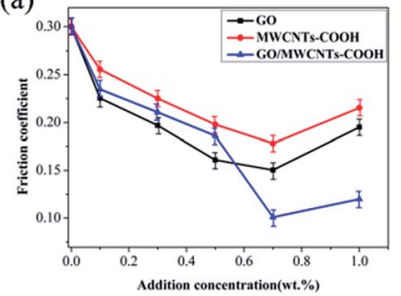

(b)

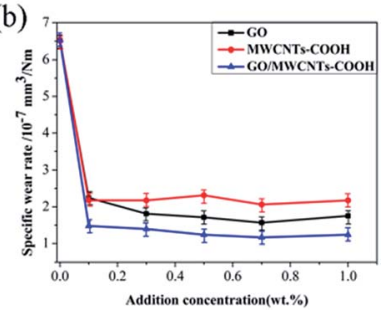

Fig. 6 Friction coefficients (a) and wear rates (b) of GO nanosheets, MWCNTs- $\mathrm{COOH}$ and GO/MWCNTs- $\mathrm{COOH}-3-1$ hybrids as additives in pure water (load: $10 \mathrm{~N}$, sliding speed: $0.0523 \mathrm{~m} \mathrm{~s}^{-1}$, duration: 30 $\min )$. 


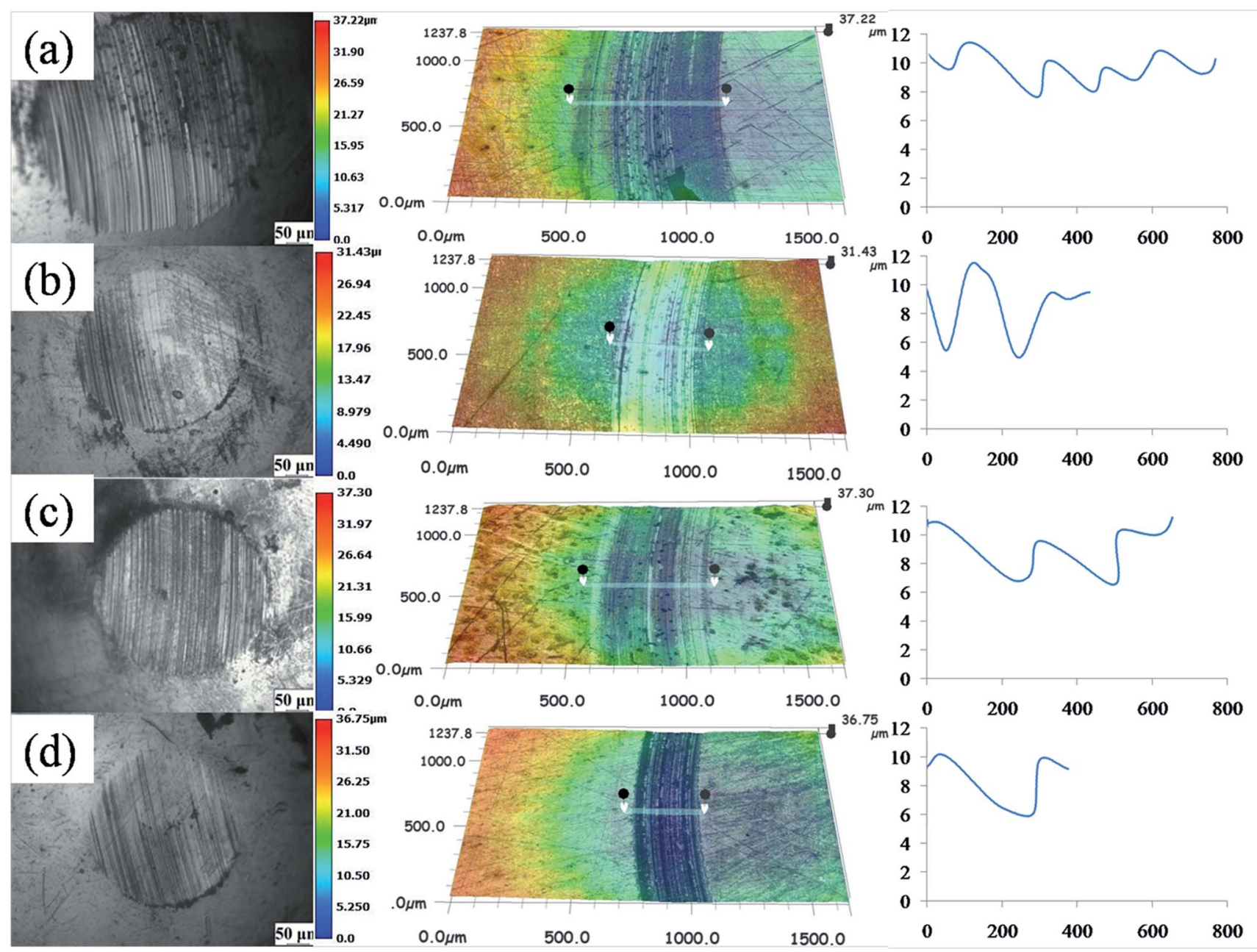

Fig. 7 Optical images of the worn surfaces of steel ball and the three-dimensional profile of wear track of the disc under pure water lubrication (a) and water added with 0.7 wt\% GO nanosheets (b), 0.7 wt\% MWCNTs-COOH (c) and 0.7 wt\% GO/MWCNTs-COOH-3-1 hybrids (d) (load: 10 $\mathrm{N}$, sliding speed: $0.0523 \mathrm{~m} \mathrm{~s}^{-1}$, duration: $30 \mathrm{~min}$ ).

Fig. 7(b-d). From the comparison of the worn surfaces, it is obvious that the wear diameter can be significantly reduced with the addition of the above three kinds of carbon additives. Besides, we can further observe that the wear spot diameter reaches minimum in case of the addition of $0.7 \mathrm{wt} \% \mathrm{GO} /$ MWCNTs-COOH-3-1 hybrids. The results indicate that $\mathrm{GO} /$ MWCNTs-COOH hybrids play a remarkable role in improving lubrication performance, which is consistent with the above results in terms of frication and wear reduction.

Fig. 8 presents SEM images of the steel disc lubricated with pure water (a) and water with $0.7 \mathrm{wt} \%$ GO nanosheets (b), 0.7 wt $\%$ MWCNTs-COOH (c) and 0.7 wt $\%$ GO/MWCNTs-COOH-31 hybrids (d). The worn surface lubricated with pure water is obviously rough with many furrows and some debris which may be caused by the contact fatigue and adhesive fatigue. In comparison, the worn surfaces lubricated by water with carbon additives show less and lighter furrows, clearly indicating that all of the three additives added into water can protect the friction surface from direct contact and reduce friction intuitively. In particular, $\mathrm{GO} / \mathrm{MWCNTs-} \mathrm{COOH}$ hybrids as water additive
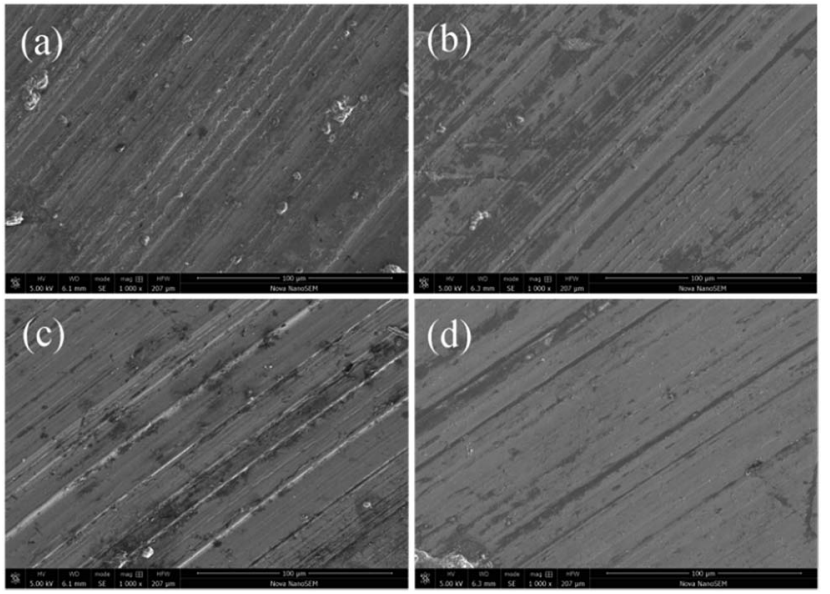

Fig. 8 SEM images of the wear track of disc under pure water lubrication (a) and water added with 0.7 wt\% GO nanosheets (b), 0.7 wt\% MWCNTs- $\mathrm{COOH}$ (c) and 0.7 wt\% GO/MWCNTs- $\mathrm{COOH}-3-1$ hybrids (d) (load: $10 \mathrm{~N}$, sliding speed: $0.0523 \mathrm{~m} \mathrm{~s}^{-1}$, duration: $30 \mathrm{~min}$ ). 

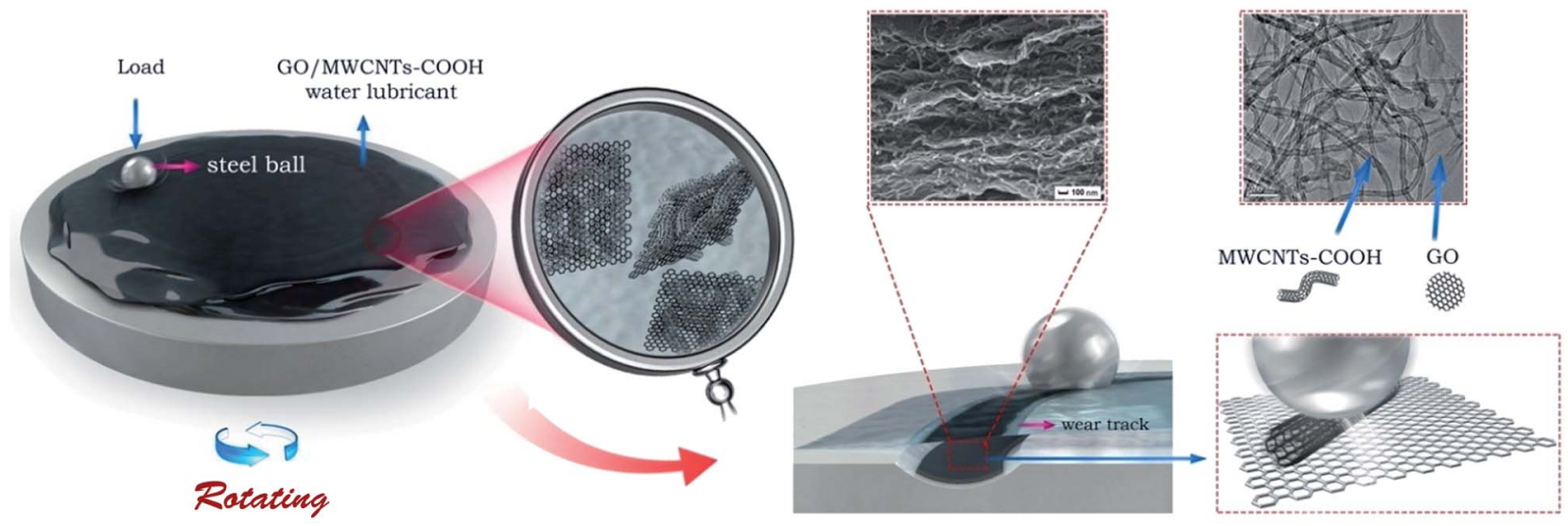

Fig. 9 The friction mechanism of GO/MWCNTs- $\mathrm{COOH}$ hybrids as additives in water lubrication.

show a smoother and flatter wear track corresponding to the lowest friction coefficient and the lowest wear rate. It can be concluded that the water with GO/MWCNTs-COOH hybrids can obtain prominent anti-friction and wear resistance ability.

In this study, the GO/MWCNTs-COOH hybrids as waterbased additive have superior wear-resisting ability as well as a very low friction coefficient has been reached at $0.7 \mathrm{wt} \%$. The friction reducing mechanism between friction interfaces with GO/MWCNTs-COOH hybrids is graphically expressed in Fig. 9. We have speculated the possible mechanism of friction reduction in the case of GO/MWCNTs-COOH hybrids dispersion in water. The synergistic effects ${ }^{26,34}$ of $\mathrm{GO} / \mathrm{MWCNTs}-\mathrm{COOH}$ hybrids make compounds can be well dispersed in water-based fluids, for that GO nanosheets and MWCNTs-COOH were combined by $\pi-\pi$ non covalent bonding extending interlayer and tube space. During the sliding, friction shear force between the steel ball and steel disc is stronger than the force of $\pi-\pi$ non covalent bonding, which easily leads GO nanosheets transfer to worn surfaces. As a result, Go could not only bear the load on the steel ball but also prevent the steel ball and steel disc from direct contact. Furthermore, MWCNTs- $\mathrm{COOH}$ in the hybrids can play a role as micro-bearings to change sliding friction into rolling friction between the worn surfaces. Therefore, an excellent lubrication performance can be achieved under the water-based lubricant with additives of GO/MWCNTs-COOH hybrids.

\section{Conclusions}

GO/MWCNTs-COOH hybrids have been synthesized via a facile vacuum filtration of solution hybrid dispersion method. There exists a synergistic effect between GO/MWCNTs-COOH hybrids that as the ratio of GO nanosheets and MWCNTs-COOH reaches $3: 1$, anti-friction and anti-wear properties of water based lubricant with GO/MWCNTs-COOH hybrids as additives come to the best. Besides, GO, MWCNTs-COOH and GO/MWCNTs$\mathrm{COOH}$ hybrids as additives can improve the tribological properties of the water-based lubricant. Particularly, the friction coefficient and wear rate gets to the minimum for the waterbased lubricant with $0.7 \mathrm{wt} \%$ of GO/MWCNTs-COOH hybrids as additive. Additionally, this study provides some guidance for further research of developing environmental friendly lubricants with excellent tribological performance.

\section{Acknowledgements}

This work was financially supported by the National Natural Science Foundation of China (51603093, 51402128, 51572113, 51372103, 51103065) and the Science and Technology Agency of Jiangsu Province (BK 20160515, BK 20140561). Dr C. Min wants to express the gratitude to Jiangsu Province for supporting this project under the innovation program (Surencaiban[2015]26). This work was supported by Key Laboratory of Superlight Materials \& Surface Technology (Harbin Engineering University), Ministry of Education.

\section{Notes and references}

1 J. M. Herdan, Lubr. Sci., 1997, 9, 161-172.

2 C. Carter, Nav. Archit., 2012, 5, 32-36.

3 S. Wen and P. Huang, Principles of tribology, Macmillan, 2012.

4 B. A. Khorramian, G. R. Lyer, S. Kodali, P. Natarajan and R. Tupil, Wear, 1993, 169, 87-95.

5 Y. S. Zoo, J. W. An, D. P. Lim and D. S. Lim, Tribol. Lett., 2004, 16, 305-309.

6 L. Joly-Pottuz, B. Vacher, N. Ohmae, J. M. Martin and T. Epicier, Tribol. Lett., 2008, 30, 69-80.

7 D. S. Lim, J. W. An and H. J. Lee, Wear, 2002, 252, 512-517. 8 J. X. Liao, W. M. Liu, T. Xu, C. R. Yang, H. W. Chen, C. L. Fu and W. J. Leng, Surf. Coat. Technol., 2005, 191, 90-95.

9 H. Cai, F. Y. Yan and Q. Y. Xue, Mater. Sci. Eng., A, 2004, 364, 94-100.

10 B. B. Johnson, M. H. Santare, J. E. Novotny and S. G. Advani, Mech. Mater., 2009, 41, 1108-1115.

11 C. Wang, T. Xue, B. Dong, Z. Wang and H. L. Li, Wear, 2008, 265, 1923-1926.

12 H. Meng, G. X. Sui, G. Y. Xie and R. Yang, Compos. Sci. Technol., 2009, 69, 606-611.

13 B. Shen and A. J. Shih, Trans. NAMRI/SME, 2009, 37, 129-136. 
14 P. Nie, C. Min, H. J. Song, X. Chen, Z. Zhang and K. Zhao, Tribol. Lett., 2015, 58, 7.

15 J. Sumfleth, X. C. Adroher and K. Schulte, J. Mater. Sci., 2009, 44, 3241-3247.

16 K. E. Prasad, B. Das, U. Maitra, U. Ramamurty and C. Rao, Proc. Natl. Acad. Sci. U. S. A., 2009, 106, 13186-13189.

17 S. Y. Yang, W. N. Lin, Y. L. Huang, H. W. Tien, J. Y. Wang, C. C. Ma, S. M. Li and Y. S. Wang, Carbon, 2011, 49, 793-803.

18 S. Chatterjee, F. Nafezarefi, N. H. Tai, L. Schlagenhauf, F. A. Nüesch and B. T. T. Chu, Carbon, 2012, 50, 5380-5386.

19 H. Y. Mao, Y. H. Lu, J. D. Lin, S. Zhong, A. T. S. Wee and W. Chen, Prog. Surf. Sci., 2013, 88, 132-159.

20 Z. Jia, T. Chen, J. Wang, J. Ni, H. Li and X. Shao, Tribol. Int., 2015, 88, 17-24.

21 S. Park and S. Kim, Electrochim. Acta, 2013, 89, 516-522.

22 Z. Jia, X. Pang, H. Li, J. Ni and X. Shao, Tribol. Int., 2015, 90, 240-247.

23 H. J. Song and N. Li, Appl. Phys. A: Mater. Sci. Process., 2011, 105, 827-832.

24 M. Sarno, A. Senatore and C. Cirillo, J. Nanosci. Nanotechnol., 2014, 14, 4960-4968.
25 O. Elomaa, V. K. Singh, A. Lyer, T. J. Hakala and J. Koskinen, Diamond Relat. Mater., 2015, 52, 43-48.

26 L. J. Cote, J. Y. Kim and V. C. Tung, Pure Appl. Chem., 2011, 83, 95-110.

27 X. Dou, A. R. Koltonow, X. He, H. D. Jang, Q. Wang, Y. W. Chung and J. Huang, Proc. Natl. Acad. Sci. U. S. A., 2016, 11, 1528-1533.

28 D. C. Marcano, D. V. Kosynkin, J. M. Berlin, A. Sinitskii, Z. Sun, A. Slesarev, L. B. Alemany, W. Lu and J. M. Tour, ACS Nano, 2010, 4, 4806-4814.

29 B. Chen, J. Wang and F. Yan, Tribol. Lett., 2012, 45, 387-395.

30 Y. Wang, Z. Ni, T. Yu, Z. X. Shen, H. Wang, Y. Wu, W. Chen and A. T. S. Wee, J. Phys. Chem. C, 2008, 112, 10637-10640.

31 J. Q. Huang, Z. L. Xu, S. Abouali, M. A. Garakani and J. K. Kim, Carbon, 2016, 99, 624-632.

32 V. Khare, M. Q. Pham, N. Kumari, H. S. Yoon, C. S. Kim, J. I. Park and S. H. Ahn, ACS Appl. Mater. Interfaces, 2013, 5, 4063-4075.

33 J. Kim, L. J. Cote, F. Kim, W. Yuan, K. R. Shull and J. Huang, J. Am. Chem. Soc., 2010, 132, 8180-8186.

34 S. Stankovich, R. D. Piner, S. T. Nguyen and R. S. Ruoff, Carbon, 2006, 44, 3342-3347. 